\title{
Dry-flowing avalanche run-up and run-out
}

\author{
D. M. MCCLunG \\ Departments of Civil Engineering and Geography, University of British Columbia, Vancouver, British Columbia V6T 124, Canada
}

\author{
A. I. MEARS \\ Natural Hazards Consultants, Gunnison, Colorado 81230, U.S.A.
}

\begin{abstract}
The prediction of run-up and run-out of dry-flowing avalanches is very important for land-use planning, design of run-out zone defenses and construction of risk maps in avalanche terrain. In this paper, we present a numerical dynamics model to predict the stop position of the tip of these avalanches when friction coefficients (internal and external), initial flow depth and incoming speed are specified for known path geometry in the run-out zone. We also compare our model to that in the Swiss guidelines and to field examples. The results of these calculations clearly define model differences and the implications of different choices of friction coefficients.
\end{abstract}

\section{INTRODUCTION}

Flowing avalanches (see Fig. 1) are those with a dense core of granular flowing snow at the base, usually with flow depth of one to several meters. Calculations of avalanche run-up for flowing avalanches are very important for the design of defenses to slow down or stop the avalanche debris core, and the problem is strongly related to calculations of run-out distances using dynamic methods.
In this paper, a practical method is introduced for calculating run-up and run-out, using avalanche-dynamics principles. The model is compared to a related model used in Switzerland which is designated as the present, standard Swiss guidelines (Salm and others, 1990) for avalanche-dynamics calculations in run-out zones. The results illustrate important differences in the mathematical and philosophical principles used in estimating stopping distances of avalanches from dynamics principles. The differences are illustrated using field-documented examples

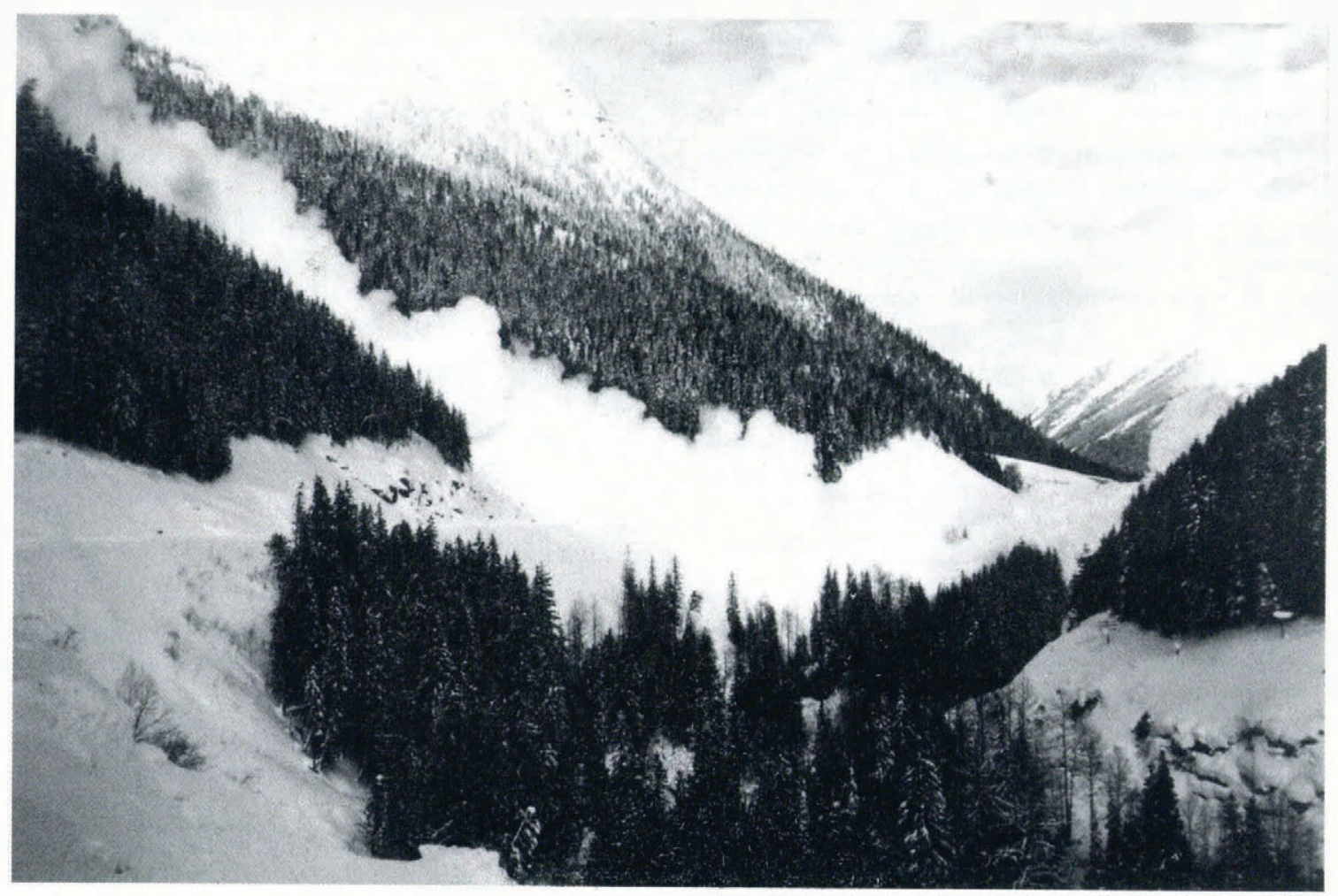

Fig. 1. Flowing avalanche enveloped in a turbulent dust cloud engaged in run-up on the side of a mountain. 
of avalanche run-up and run-out and theoretical comparisons using identical model parameters.

The focus of our paper is a simple, practical method for run-up or run-out prediction similar to that proposed in the Swiss guidelines (Salm and others, 1990). Thus, our work is intended to apply to only one, small but important, part of the avalanche-dynamics problem. Specifically, we provide a simple theoretical framework from which it is possible to calculate run-up or run-out for avalanches containing dry snow, provided that the friction coefficients (including internal friction), flow depth of material approaching the run-up or run-out slope, and slope geometry are known.

We do not address here the important question of how to estimate incoming speeds and friction coefficients. We do, however, provide our prescription of how friction coefficients enter the run-up (or run-out) dynamics problem, since our view differs from the somewhat traditional one expressed in the Swiss guidelines. Due to the complexity of the avalanche-dynamics problem and the simplifications introduced for one-dimensional motion, it probably is not yet possible to say definitely which view of this important question is most nearly correct. Our comparisons with field examples do not completely resolve this issue: high uncertainty remains with respect to friction-parameter input.

\section{FLOW AND BOUNDARY CONDITIONS}

We consider first a model for run-up and run-out calculations based upon solution of the dynamic-equilibrium equations and continuity proposed by Hungr and McClung (1987) and modeling at slope transitions proposed by Takahashi and Yoshida (1979) and Takahashi (1991) for the related problem of debris-flow dynamics. The model is a depth-averaged, one-dimensional formulation with constant densities assumed within, $\bar{\rho}$, and at the top of the core $\rho_{\mathrm{t}}$, of the flowing avalanche.

In order to develop a practical dynamics model relevant to run-up (and run-out) problems, it is very important to begin from a realistic physical picture of the avalanche-flow conditions. Since, in reality, the processes involved are very complex, it would be very difficult to model them in great detail. One must, then, rely on a proper interpretation of the trends in the processes involved to arrive at a model with the correct form of boundary conditions. The boundary conditions will be crucial for determining the dynamic behavior of snow avalanches.

Direct observations of the flow conditions inside avalanches are very rare and the information available is not very precise. We are concerned here with physical modeling of the conditions at the top and bottom of the flowing snow as well as with the internal friction between snow particles. Observations, measurements of flow conditions and avalanche impact pressures indicate that the core of flowing avalanches is a dense granular material (McClung and Schaerer, 1985, 1993; Gubler and others, 1986; Salm, 1993). By "dense", we mean that the concentration of solid material (volume fraction filled by solid material) is high enough that the probability of frequent collisions between particles is high during all stages of the flow. However, during run-out and run-up there will also be considerable rubbing friction between the particles as they become close enough for enduring particle contact. In the final stage, locking takes place and static friction is approached. The volume fraction filled by solids has not been precisely measured in run-up and runout problems. However, back calculations by McClung and Schaerer (1985) yielded estimates of $3050 \%$ solids concentration within the flow for measurement in the track (or transport zone) before significant deceleration and run-out deposition took place. These measurements were taken just above the ground surface but are not precise enough to give estimates relevant to the crucial boundary condition at the bottom. In general, we expect the volume concentration of solids to increase from the top to the bottom of a flowing avalanche.

If the estimates of solids concentration from impact data are reasonable, very important implications arise with respect to run-up and run-out problems. In the final stages of motion, we may expect the solids concentration to be even higher than the $30-50 \%$ range measured in the track. Gubler and others (1986) estimated from precise radar measurements that the flowing material shows concentrated shearing deformation at the bottom with very little internal shearing in the main body of the flow (Salm, 1993). This information is consistent with the picture that the relevant volume concentration of solids is high for run-up and run-out problems, with perhaps a slightly reduced value within the zone of active shearing at the bottom.

Observations of actual dry deposits from large avalanches show that particle size decreases rapidly with depth into the deposit. Particle sizes at the surface are typically in the range $1-10 \mathrm{~cm}$, but deeper in the deposit particles are of much smaller sizes down to the millimeter scale. These observations show that there have been intense interactions (collisions) between particles and with the sliding surface at some stages of their travel down the mountain. Again, the indication is that the flow must be considered dense: the collision mean free path is smaller than the distance between the particles. In addition, since the density of the fluid (air) is at least $10^{-2}-10^{-3}$ that of the particles, these two trends (low fluid density and high volume concentration of particles) mean that we expect momentum transfer to be due to particle collisions and rubbing friction between particles, with the fluid ignored in the mechanical description. This is particularly likely to be true in run-up and run-out problems dealing with the final stages of motion. McClung (1990) has discussed this physical condition extensively.

For run-up and run-out, then, we consider the motion of a dense core of material with lower-density material suspended in turbulent eddies around the upper surface of the core. Takahashi (1991) took the bold step of uncoupling turbulent fluid processes and particle-particlecollision and rubbing-friction effects to enable the basal shear resistance to be written as the sum of two terms. In what follows, we adopt Takahashi's strategy initially, but in the final formulation of our model we do not retain the uncoupled form to express the motion resistance at the upper and lower boundaries. The assumption that the basal shear resistance can be written as a sum (Equation (1) below) has been traditional in avalanche-dynamics 
formulations since Voellmy (1955) and Salm (1966). Since the Swiss guidelines essentially contain this assumption, it is retained here initially, but it is not contained in our model. At the bottom of the flow, then, we take the downslope resistance, $\tau_{\mathrm{b}}$, to motion as the sum of two terms:

$$
\tau_{\mathrm{b}}=T+\tau^{\prime}
$$

where $T$ is resistance due to particle interaction with the sliding surface and adjacent particles within the flow, and $\tau^{\prime}$ is turbulent friction generated by any turbulence within the interstitial air at the base of the flow. For the dense flow at the base of the flow, however, we assume that $\tau^{\prime} \ll T$. This is because the high density (volume fraction) of particles at the base of the flow will prevent turbulence from forming within the interstitial air. Furthermore, we assume (Dent, 1986, 1993; McClung, 1990 ) that bottom friction (due to collisions and rubbing) is coupled to the normal stress provided by the overburden of material by a dynamic coefficient of friction, $\mu$, which may in general depend on rate of shearing and volume fraction as well as roughness and condition of the sliding surface. Basal drag will always be dominant in run-out and run-up, with drag at the top of the flow often being negligible. We then adopt a dynamic Coulomb-type relation

$$
\tau_{\mathrm{b}}=\mu \bar{\rho} g \bar{h} \cos \psi
$$

for our definition of basal resistance. In Equation (2), $\bar{\rho}$ is depth-averaged density, $\bar{h}$ is mean flow depth along the run-up (or run-out) slope and $\psi$ is slope angle. We later derive an approximate expression for $\bar{h}$ and replace it by the expected mean deposition depth in the run-out zone. Dent (1993) shows examples of how $\mu$ may vary with speed, particle-restitution coefficient and inter-particle friction for dense, rapidly sheared granular materials.

At the top of the core, we envision resistance to motion being represented by turbulent drag due to air/snow dust by representing the upper surface of the flow. If one adopts Takahashi's strategy, an equation analogous to Equation (2) can be written for the top of the flow, but in this case $T$ is negligible and $\tau^{\prime}$ is of primary importance. The upper surface of the core presents a rough surface which generates friction as the avalanche is transported along the incline with speed, $v$. The upper surface of the core is envisioned as consisting of a rough surface with saltating particles at the top immersed in a snow-dust and air mixture suspended in turbulent eddies. The drag at the top of the flow is represented as:

$$
\tau_{\mathrm{t}}=\frac{1}{2} \rho_{\mathrm{t}} C_{\mathrm{D}} v^{2}
$$

where $\rho_{\mathrm{t}}$ is density of the snow-dust-air mixture and is about $10 \mathrm{~kg} \mathrm{~m}^{3}$ (McClung, 1990) and $C_{\mathrm{D}}$ is a drag coefficient for turbulent flow over a rough upper periphery of the core. Following McClung (1990), we estimate that the value of $C_{\mathrm{D}}$ is about 0.01 , from Schlicting (1972). In at least some problems of run-up and run-out, we believe that the contribution of Equation (3) to stopping dynamics may often be very small if not negligible). For completeness, however, we will retain Equation (3) to represent drag at the top of the flow instead of prescribing a free surface there.

For Equation (2), $\bar{\rho}$ is the mean density of material in the core of the avalanche. Since the mixture there may consist of snow particles (a mixture of ice and air) and air, we may write

$$
\bar{\rho}=\rho_{\mathrm{s}} C+\rho_{\mathrm{A}}(1-C)
$$

for the mixture, where $C$ is the volume fraction filled by snow particles, $\rho_{\mathrm{s}}$ is the density of snow particles, and $\rho_{\mathrm{A}}$ is the air density. With $C$ in the range $0.30-0.50$, as estimated by McClung and Schaerer (1985), and with $\rho_{\mathrm{s}}$ in the range $200-500 \mathrm{~kg} \mathrm{~m}^{-3}$ (McClung and Schaerer, 1993 ) and $\rho_{\mathrm{A}}=1 \mathrm{~kg} \mathrm{~m}^{-3}$ (density of air), $\bar{\rho}$ is in the range of about $100-300 \mathrm{~kg} \mathrm{~m}^{-3}$, or at least ten times $\rho_{\mathrm{t}}$, the density at the top of the flow. At the bottom of the flow, due to destructive collisions, it is possible that the particles consist of millimeter-size individual ice grains $(917 \mathrm{~kg}$ $\mathrm{m}^{-3}$ ), and the flow density may be as high as $450 \mathrm{~kg} \mathrm{~m}^{-3}$.

In the interior of the flow, it may be necessary to account for internal friction between snow particles in run-up and run-out problems. Salm (1993) points out that internal shearing is only possible if the internal friction angle $\phi$ is less than the slope angle in first approximation. Since run-up and run-out problems are, from field observations, those in the last stages of motion in which at least some of the material is "locked" or not undergoing rapid shearing, we must have a mechanism to account for the internal resistance in the flow mechanics. Salm $(1966,1993)$ proposes that allowance be made for passive snow pressure analogous to passive earth pressure for the compressive states of stress expected in run-up and run-out problems. The longitudinal passive snow pressure (per unit width) may be represented as (Craig, 1988):

$$
\bar{\sigma}_{\mathrm{p}}=\frac{1}{2} \bar{\rho} g k_{\mathrm{p}} h_{0}^{2} \cos \psi_{0}
$$

where $(\phi$ is internal friction angle)

$$
\begin{array}{ll}
k_{\mathrm{p}}=\frac{\cos \psi_{0}+\sqrt{\cos ^{2} \psi_{0}-\cos ^{2} \phi}}{\cos \psi_{0}-\sqrt{\cos ^{2} \psi_{0}-\cos ^{2} \phi}} & \phi \geq \psi_{0} \\
k_{\mathrm{p}}=1 & \phi \leq \psi_{0} .
\end{array}
$$

In Equation (6), cohesion is ignored, and $h_{0}$ and $\psi_{0}$ represent flow depth and slope angle on entering the runout zone, respectively. For $\phi \leq \psi_{0}$, Equation (5) reduces to the fluid analogy introduced by Hungr and McClung (1987) for which $k_{\mathrm{p}}=1$. For $\psi_{0}=0^{\circ}$, Equation (6) reduces to the expression given by Salm (1993). There is considerable uncertainty with respect to the role of passive snow pressure in avalanche dynamics. Since the constitutive equation for flowing snow is unknown, our formulation takes the simplest possible form by specifying a constant internal friction angle. Below we discuss some preliminary suggestions for a rough determination of $\phi$ based upon Salm's (1993) discussion and our own observations. Salm and others (1990) and Salm (1993) estimate for run-out zones based upon avalanche deposits that $\phi$ is about $25^{\circ}$. This estimate $\left(\phi=25^{\circ}\right)$ is recommended in the Swiss guidelines (Salm and others, 1990), and we shall also retain this estimate for run-up and run- 
out problems. With $\phi=25^{\circ}$ and $\psi_{0}=0^{\circ}$, Equation (6) gives $k_{\mathrm{p}}=2.5$. Equation (6) with $\phi=25^{\circ}$ predicts that locking in the flow will begin at slope angles of about $25^{\circ}$. Thus passive snow pressure will begin to become a factor in run-up and run-out problems for slope angles less than $25^{\circ}$, if $\phi$ is taken as $25^{\circ}$. This seems to be reasonable as a rough estimate, as speeds in large, dry avalanches are usually beginning a decelerating phase for such slope angles (Gubler and others, 1986), and the flowing snow should be entering a compressive phase.

Evidence from avalanche deposits (described above) shows that particle sizes decrease rapidly below the surface of deposits to produce a uniform distribution of particles of small size. This indicates that shearing deformations and intense destructive collisions of particles have taken place through the depth of the flow at some stages of motion. Salm (1993) points out that $\phi$ has never been estimated in flowing snow. Static values for $\phi$ are estimated by McClung (1987) in the range $50-60^{\circ}$; such values may be reasonable for deposited snow, but here we provide estimates during run-up and run-out for which we believe the static estimates $\left(50-60^{\circ}\right)$ would be too high. Physically, $k_{\mathrm{p}}$ then depends on flow conditions and state of stress, but for our practical work we estimate it by choosing a reasonable value for $\phi$ and then incorporate geometric effects using Equations (5) and (6). Field estimates of impact pressures in the transport zone (track) by McClung and Schaerer (1985) show that pressures in large, dry avalanches have a highly fluctuating component for a slope angle of $31^{\circ}$. These measurements indicate that the material is not in a completely locked state until lower slope angles are encountered in the deposition zone. These observations make it reasonable that passive snow pressure begins to take effect as the mass approaches the deposition zone consistent with a value for $\phi$ near $25^{\circ}$. We recommend adopting an angle, $\phi$, with an approximate value intermediate between $0^{\circ}$ (no friction) and 50-60 (static value from in situ tests) to describe flowing snow in the final stages of run-up or run-out. Accordingly, we have chosen $\phi=25^{\circ}$, consistent with the Swiss guidelines (Salm and others, 1990).

\section{LEADING-EDGE THEORETICAL MODEL}

For run-up and run-out, we adopt a one-dimensional model to calculate the position of the leading edge of the avalanche, with quantities averaged through the depth of the flowing snow measured perpendicular to the surface over which the avalanche is flowing. We consider the flow as incompressible so that the density of material in the body of the flowing snow is assumed constant. We also assume that the discharge per unit width, $Q\left(\mathrm{~m}^{2} \mathrm{~s}^{-1}\right)$, is constant throughout run-up or run-out. The assumption of constant $Q$ is a very rough approximation. Consistent with the background material above, the resistive forces are a dynamic Coulomb friction force at the bottom of the avalanche (Equation (2)) and a turbulent resistive force at the top and around the upper periphery of the avalanche body (Equation (3)). Note that our boundarycondition formulations do not require the assumption implied by Equation (1) of decoupling the stress terms, even though this assumption is rooted in most avalanche- dynamics models since Voellmy's (1955).

Considering the problem of run-up, following Hungr and McClung (1987) and Takahashi (1991), we express Newton's second law (see Figure 2 for the geometry) as:

$$
\frac{\mathrm{d}(\bar{\rho} \bar{h} v x)}{\mathrm{d} t}=T_{1}+T_{2}+T_{3}+T_{4}+T_{5} .
$$

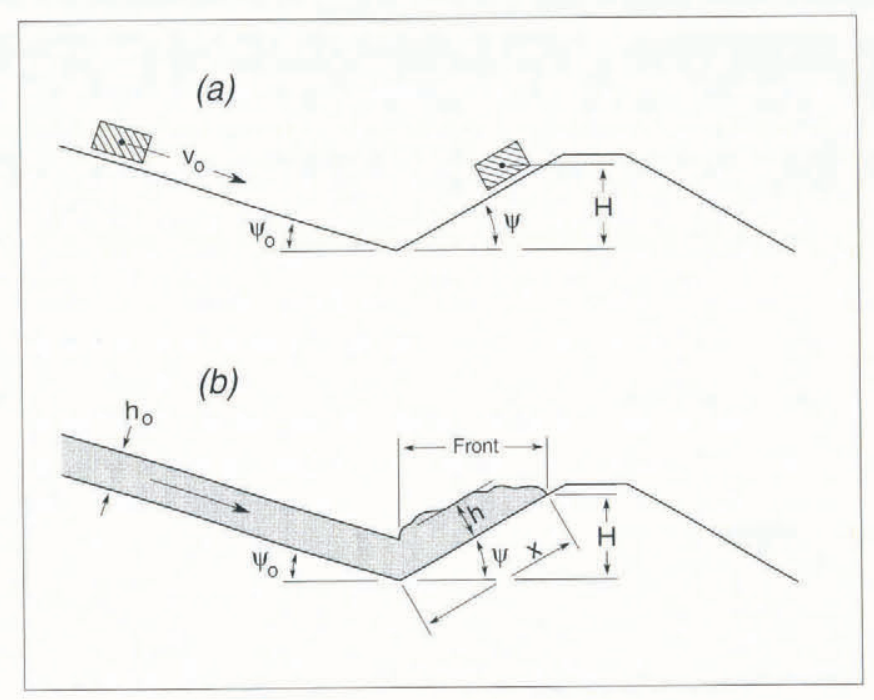

Fig. 2. Schematic of flowing-avalanche run-up on an adverse slope: (a) lumped-mass or centre-of-mass model, (b) leading-edge model.

The quantities are expressed as force per unit width of the flow, and terms $T_{1}-T_{5}$ are driving and resistive forces affecting motion, $\bar{h}$ is mean flow depth along the run-out slope, and $x$ is distance along the run-out slope measured from zero at the beginning of the run-out slope. Terms $T_{1}-T_{5}$ are given below (force per unit width); of these, $T_{3}$ and $T_{4}$ are always resistive terms.

\section{$T_{1}$ Driving force $\bar{\rho} g \bar{h} x \sin \psi$}

$T_{2}$ Momentum flux $\bar{\rho} h_{0} v_{0}^{2} \cos \left(\psi_{0}-\psi\right)$ approaching the run-out or run-up slope, where $\psi_{0}, v_{0}$ and $h_{0}$ are initial slope angle, speed and flow depth, respectively

$T_{3}$ Dynamic Coulomb resistive force (at the bottom) $-\mu \bar{\rho} g \bar{h} x \cos \psi$

$T_{4}$ Turbulent resistive force (at the top) $-\frac{1}{2} \rho_{\mathrm{t}} C_{\mathrm{D}} v^{2}$

$T_{5}$ Passive snow-pressure force term $\frac{1}{2} \bar{\rho} g h_{0}{ }^{2} k_{\mathrm{p}} \cos \psi_{0}$ $\cos \left(\psi_{0}-\psi\right)$.

Equation (7) is derived for a very general momentum principle for constant supply to the flow. The momentum flux term $T_{2}$ is calculated as the incoming mass flux (per unit width) times the incoming velocity, with the velocity taken as the mean value through the depth of flow. It represents the discharge (or supply) of momentum to the run-out or run-up slope. See Appendix B for an explanation of this term.

By analogy to fluid dynamics, we assume supercritical flow at the beginning of the run-out slope so that conditions upstream are not influenced. Typical speeds and flow depths for avalanches indicate this is a good assumption. The other terms on the righthand side of Equation (7) come from the sum of all the forces acting on the flowing avalanche mass, including gravity, friction at the top and bottom and internal, passive snow pressure. 
These formulae differ from Hungr and McClung's (1987) for terms $T_{4}$ and $T_{5}$. In $T_{4}$, we assume here that turbulent resistive force acts only at the top and upper surface, not the bottom, of the avalanche. In $T_{5}$, we have included friction between the snow particles (for $\phi \geq \psi_{0}$ ) as expressed in Equation (6). In order to solve for the runout or run-up distance, we solve Equation (7) for the distance, $x_{\mathrm{R}}$, when $v=0$ with the initial condition that $t=0$ when $x=0$. In our formulation, slope angles $\left(\psi, \psi_{0}\right)$ are taken positive if the slope is downward from horizontal and negative if upward (adverse slopes). In Equation (7), $\psi$ is taken positive on the approach slope and negative on run-up slope (or for adverse slopes in run-out). In addition, we must invoke the depthaveraged, integrated continuity equation so that mass is conserved:

$$
\bar{h} x=h_{0} v_{0} t .
$$

The derivation of Equation (8) requires the assumption of constant mean dynamic flow depth, $\bar{h}$, in the run-up (or run-out) zone.

Rearrangement of Equation (7) gives:

$$
\frac{\mathrm{d}}{\mathrm{d} t}(v t)=-G_{0} t+V-D_{0} v^{2} t
$$

where $G_{0}=g(\mu \cos \psi-\sin \psi)$

$$
V=v_{0} \cos \left(\psi_{0}-\psi\right)\left(1+\frac{k_{\mathrm{p}} g h_{0} \cos \psi_{0}}{2 v_{0}^{2}}\right)
$$

with

$$
D_{0}=\frac{1}{2}\left(\frac{\rho_{\mathrm{t}}}{\bar{\rho}}\right) \frac{C_{\mathrm{D}}}{\bar{h}} .
$$

On the run-up or run-out slope we seek a numerical solution of Equations (8) and (9) for $v$ as a function of time. The run-up or run-out distance is then given by the integral of $v$ from $t=0$ until $t=t_{\mathrm{R}}$, the time taken on the run-up slope until the front of the avalanche stops. It is of interest to compare the two resistance terms $G_{0} t$ and $D_{0} v^{2} t$ for a run-up slope. The ratio of these terms is: $G_{0} / D_{0} v^{2}$ where, on the adverse run-up slope, $G_{0}$ is represented by $g(\sin |\psi|+\mu \cos |\psi|)$, i.e. $\psi$ is negative.

Typical values for $D_{0}$ result from (McClung, 1990) $\rho_{\mathrm{t}} / \bar{\rho} \simeq 0.1, \bar{h}=3 \mathrm{~m}, C_{\mathrm{D}}=0.01$ and in run-up problems. If $\psi=30^{\circ}, \mu=0.3$, and $v=20 \mathrm{~m} \mathrm{~s}^{-1}$, the ratio becomes $G_{0} / D_{0} v^{2}=112$. For our model, therefore, in some cases of practical interest, the term $D_{0} v^{2} t$ may be ignored in run-up (and run-out) problems, and drag may be attributed to dynamic Coulomb drag at the base of the avalanche. When the term $D_{0} v^{2} t$ is ignored, an analytical solution is available and the run-out distance is

$$
X_{\mathrm{R}}=\frac{V^{2}}{G_{0}}
$$

and the run-up height is

$$
H=\frac{V^{2}}{G_{0}} \sin \psi .
$$

Following Salm (1993), we derive an approximate expression for the mean deposition depth on the run-up (or run-out) slope. Neglecting the turbulent term, the solution for the speed along the deceleration slope is:

$$
v=\sqrt{G_{0}}\left(X_{\mathrm{R}}-x\right)^{\frac{1}{2}} .
$$

For an approximate mean flow depth in the run-up (or run-out) zone, we assume from conservation of mass, following Salm (1993), a constant supply of mass per unit width entering into the run-up (or run-out) zone until the tip comes to rest. The balance for the flux of material (per unit width) is:

$$
Q=h v=h_{0} v_{0}
$$

where $h$ is instantaneous flow depth during run-out.

Equation (15) is written for one-dimensional motion, and if the approximations $\mathrm{d} h / \mathrm{d} x \ll 1$ and constant density are assumed, simplification results. Integration of Equation (15) all along the deposition zone, with $h=\bar{h}$ taken as constant, gives the mean deposition-zone depth (Salm, 1993):

$$
\bar{h} \simeq \frac{h_{0} v_{0}}{\bar{v}} .
$$

In Equation (16), quantities with a bar $(\bar{v})$ are averaged along the length of the run-up or run-out zone. Integration of Equation (14) (assuming neglect of turbulent drag) gives:

$$
\bar{h} \simeq \frac{3}{2} \frac{h_{0} v_{0}}{V}
$$

where $V$ is given by Equation (10). With neglect of passive snow pressure and the slope-angle momentum correction $\left(\cos \left(\psi_{0}-\psi\right) \rightarrow 1\right)$, Equation (17) predicts that $\bar{h}$ is about $1.5 h_{0}$.

When slope-angle momentum correction is important (such as in run-up), Equation (17) predicts that $\bar{h}$ can be as high as $3 h_{0}$. Ficld measurements show that this approximate range of values $\left(1.5 h_{0}\right.$ to $\left.3 h_{0}\right)$ is reasonable. The approximations and one-dimensional character of Equation (17) mean that only rough estimates are provided. In problems for which turbulent drag is important, the estimate in Equation (17) could be revised by numerical integration to derive the speed estimate analogous to Equation (14) which is given for neglect of turbulent drag. However, since Equation (17) is only a rough estimate, and since we expect turbulent drag to be small in many run-up and run-out problems, this added sophistication is probably unnecessary. Following Salm (1993), for practical problems we now replace $\bar{h}$ in our theoretical model with $\bar{h}$ given by Equation (17). This assumption is equivalent to taking the mean deposition depth as our estimate of the mean flow depth in the runout or run-up zone.

Equation (17) provides only an approximate estimate (e.g. Salm, 1993): dynamic dependence on flow-depth changes and turbulence during run-out are ignored and constant discharge is assumed. In reality, input discharge is 
expected to decrease from a certain time after the passage of the avalanche front. Since deceleration and deposition processes relate to non-equilibrium states, an expression like Equation (17), derived from idealized simplifications, is only a rough estimate. Avalanche-flow height variations and deposition depth often display two- and threedimensional effects, not included in Equation (17).

\section{LUMPED-MASS MODELS}

Models containing the assumption that motion may be described by the centre of mass of the avalanche have been the most popular for run-up and run-out problems. The models of Voellmy (1955), Salm (1979), Perla and others (1980) and Salm and others (1990) are mathematically equivalent to motion description as if the avalanche mass were concentrated at a point at the centre of mass. The model of McClung (1990) is also a centre-of-mass model but is intended only for speed estimates, not runout estimates. Lumped-mass models have two disadvantages in run-up and run-out problems:

(1) Since motion description is with respect to the centre of mass instead of the tip of the avalanche, such models predict shorter run-up or run-out (Hungr and McClung, 1987; Chu and others, 1995) if the same friction coefficients are used.

(2) It is not possible to include passive snow pressure explicitly in the run-up or run-out formulation since only external forces can be specified in a point-mass model.

Salm (1979), Perla and others (1980) and McClung (1990) have derived the differential equation for the lumped-mass models analogous to Equation (9):

$$
\frac{1}{2} \frac{\mathrm{d} v^{2}}{\mathrm{~d} s}=-G_{0}-D_{0} v^{2} .
$$

In Equation (18), $\mathrm{d} s$ is an element of path length along the incline. For the simple geometry of Figure 2, we assume, following Perla and others (1980), that only the slope-parallel component of velocity is transferred on to the run-up or run-out slope: $v_{0} \rightarrow v_{0} \cos \left(\psi_{0}-\psi\right)$ when $\psi_{0}$ is greater than $\psi$. The solution to Equation (18) is then (e.g. Salm, 1979; Perla and others, 1980):

$$
v^{2}=\left[\left(v_{0} \cos \left(\psi_{0}-\psi\right)\right)^{2}+V_{0}^{2}\right] \mathrm{e}^{-2 D_{0} x}-V_{0}^{2}
$$

where $V_{0}^{2}=G_{0} / D_{0}$. Equation (19) is mathematically equivalent to speed estimates in the Swiss guidelines (Salm, 1993) except that the Swiss guidelines do not account for the momentum loss at slope transitions when the slope angle decreases (it is assumed that $\left.\left(\cos \left(\psi_{0}-\psi\right) \rightarrow 1\right)\right)$. Also, in the guidelines, the parameter $D_{0}$ is envisioned as accounting for turbulent drag at the base of the flow instead of at the top of the flow as we envision it. Appendix A explains the relation between $D_{0} \bar{h}$ and its alternative representation in the Swiss guidelines $(g / \xi)$ for our model and the Swiss guidelines. With the substitutions, $D_{0}=g / \xi \bar{h}$ (Swiss guidelines) instead of

$$
D_{0}=\frac{1}{2}\left(\frac{\rho_{\mathrm{t}}}{\bar{\rho}}\right) \frac{C_{\mathrm{D}}}{\bar{h}} \text { (our model), } \xi \rightarrow 2\left(\frac{\bar{\rho}}{\rho_{\mathrm{t}}}\right) \frac{g}{C_{\mathrm{D}}}
$$

and $\cos \left(\psi_{0}-\psi\right) \rightarrow 1$, the speed equations of the Swiss guidelines are recovered.

The solution to Equation (18) for the run-out distance is:

$$
X_{\mathrm{R}}=\frac{1}{2 D_{0}} \ln \left(1+\frac{v_{0}^{2} \cos ^{2}\left(\psi_{0}-\psi\right)}{V_{0}^{2}}\right) \text {. }
$$

For the run-up height, we get $(\psi$ is taken negative)

$$
H=\frac{\sin \psi}{2 D_{0}} \ln \left(1+\frac{v_{0}^{2} \cos ^{2}\left(\psi_{0}-\psi\right)}{V_{0}^{2}}\right)
$$

With the substitutions above, $\cos \left(\psi_{0}-\psi\right) \rightarrow 1$ and $D_{0}=g / \xi \bar{h}$, Equation (20) is identical to that given for run-out distance in the guidelines (Salm, 1993). Using L'Hospital's rule, in the limit as $D_{0} \rightarrow 0$ (neglect of turbulent drag), Equation (20) reduces to

$$
X_{\mathrm{R}}=\frac{1}{2} \frac{v_{0}^{2} \cos ^{2}\left(\psi_{0}-\psi\right)}{G_{0}} .
$$

For run-up, we take $\psi$ negative in $G_{0}$, and the run-up height is:

$$
H=\frac{v_{0}^{2} \cos ^{2}\left(\psi_{0}-\psi\right)}{2 G_{0}} \sin \psi
$$

Equations (22) and (23) may be compared to Equations (12) and (13) for the leading front model. If passive snow pressure is neglected, Equations (12) and (13) predict exactly twice the run-out or run-up. This comparison shows a fundamental difference between the models: the leading-edge model always predicts longer run-up or runout if the same incoming speed and friction coefficients are used, because it simulates the motion of the tip of the avalanche (instead of the centre of mass) and because it contains passive snow pressure explicitly. Hungr and McClung (1987) have emphasised these differences previously. In addition to a different momentum formulation, the Swiss guidelines (Salm and others, 1990; Salm, 1993) contain no provision for momentum loss as slope angle decreases. Experimental data from small-scale experiments on granular flows show that the correction, $v_{0} \rightarrow v_{0} \cos \left(\psi_{0}-\psi\right)$, is important in run-up (Chu and others, 1995).

To compare solutions for the leading-edge model and the centre-of-mass approach for cases in which turbulent drag is important, the numerical solution to Equations (7), (8) and (17) may be compared to Equations (20) and (21). To complete the model for the Swiss guidelines (Salm and others, 1990; Salm, 1993) it is necessary to introduce the mean run-out zone deposition depth analogous to Equation (17) for our model. Salm (1993) gives the expression from the Swiss guidelines from an engineering hydraulics argument:

$$
\bar{h}=h_{0}+\frac{v_{0}^{2}}{4 g \lambda}
$$


where $\lambda=\tan ^{2}\left(45^{\circ}+\phi / 2\right)$. This can be related to our expression for passive snow pressure by substitution: $\lambda \rightarrow k_{\mathrm{p}} \cos \psi_{0}$ with $\psi_{0}=0^{\circ}$. In other words, $\cos \psi_{0}$ is explicitly taken as 1 in the Swiss guidelines instead of accounting for the multiplier $\cos \psi_{0}$ as is usual in passivepressure theory Craig, 1988). For comparison between the leading-edge and lumped-mass models in the next section, we shall specify a value for $\phi$ to achieve the same assumptions.

For run-up estimates, the guidelines (Salm and others, $1990)$ simply specify:

$$
H=h_{0}+\frac{v_{0}{ }^{2}}{2 g \lambda}
$$

for an approximate estimate of run-up from analogy to engineering hydraulics.

\section{MODEL COMPARISONS AND FIELD EXAMPLES}

In order to calculate run-out or run-up from our model or the Swiss guidelines, one must have estimates of $v_{0}, h_{0}, \mu$. $\phi$, and $D_{0}$ (our model) or $\xi$ (Swiss guidelines). In addition, the geometry must be known $\left(\psi_{0}\right.$ and $\left.\psi\right)$. Field examples in which all of these parameters are known accurately are virtually non-existent; one must always rely on theoretical estimates for the parameters to some extent. In this section, we compare the models theoretically by using the same geometry and parameter estimates with $v_{0}$ varying, and we also attempt comparison for field examples in which at least the incoming speed, $v_{0}$, is measured and path geometry is known.

\section{(i) Model comparison}

Figure 3 shows model comparisons for run-out with the same input parameters: $\psi_{0}=25^{\circ}, \psi=8^{\circ}, \phi=25^{\circ}$ with input flow depth $(0.5-2.5 \mathrm{~m})$ and approach speed $(15-$ $35 \mathrm{~m} \mathrm{~s}^{-1}$ ) varied. For this example, we have used friction parameters specified by Salm (1993), $\mu=0.155, \xi=$ $1000 \mathrm{~ms}^{2}$, and equivalent to suggestions in the Swiss guidelines for large avalanches. The results show that the predictions are similar, with the leading-edge model usually not always) producing longer (more conservative) run-out for initial flow depths $\geq 1 \mathrm{~m}$. In Figure $3 \mathrm{~b}$ the deposition (flow) depths are shown as input to the calculations of Figure 3a. The run-out distance predictions for the Swiss guidelines are significantly boosted by assuming very high deposition depths. In the guidelines, as in our model, the dynamic flow depth is taken constant during run-out and is equated to mean deposition depth. Salm (1993) showed that deposition depths predicted by the Swiss guidelines may be higher than the real ones by a factor of about 3. Salm (1993) has noted that the Swiss guidelines use unrealistically high flow depths. If the same flow depths were assumed for both models for the calculations in Figure 3, the guidelines would predict much shorter run-out than the leading-edge model because the guidelines are essentially a centre-of-mass model (see discussion above). Another difference is that the leading-edge model accounts for momentum loss at the slope transition whereas the guidelines do not. This is
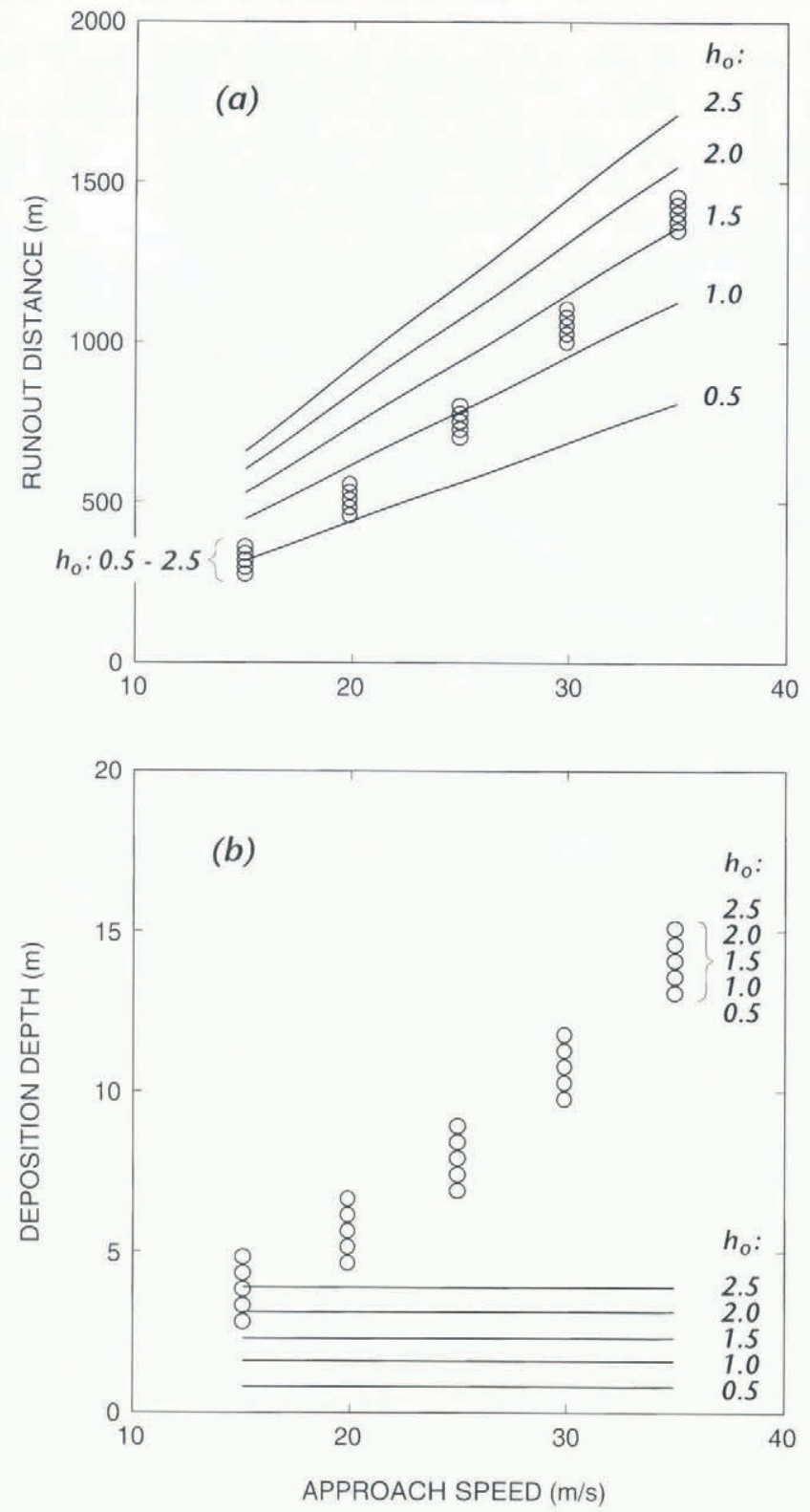

Fig. 3. (a) Run-out predictions for the leading-edge model (-) and the Swiss guidelines (centre-of-mass model) (O) as a function of approach-flow depth $\left(h_{0}\right)$ and approach speed $\left(v_{0}\right)$. Calculations are shown for $h_{0}=0.5$, 1.0, 1.5, 2.0 and $2.5 \mathrm{~m}$. (b) Deposition flow depths for the calculations in (a); $\psi_{0}=25, \psi=8^{\circ}, \xi=1000 \mathrm{~ms}^{2}$, $\mu=0.155, \phi=25^{\circ}$.

not usually very important in run-out problems, but it is important in run-up (see Chu and others (1995) and the discussion below) where the slope-angle transition is abrupt. For the calculations in Figure 3, turbulent drag is important and influences the results.

Figure 4 shows run-out comparison for different friction parameters than in Figure $3: \psi_{0}=25^{\circ}, \psi=8^{\circ}$, $\mu=0.3, \xi=19620 \mathrm{~ms}^{-2}, \phi=25^{\circ}$. See Appendix A for an explanation of the choice of $\xi$. In this example, turbulent drag will be small, as we envision for run-out or run-up problems. For the results in Figure 4, the calculations for the Swiss guidelines are essentially independent of initial flow depth when initial speed is specified, because for the guidelines flow depth enters only 

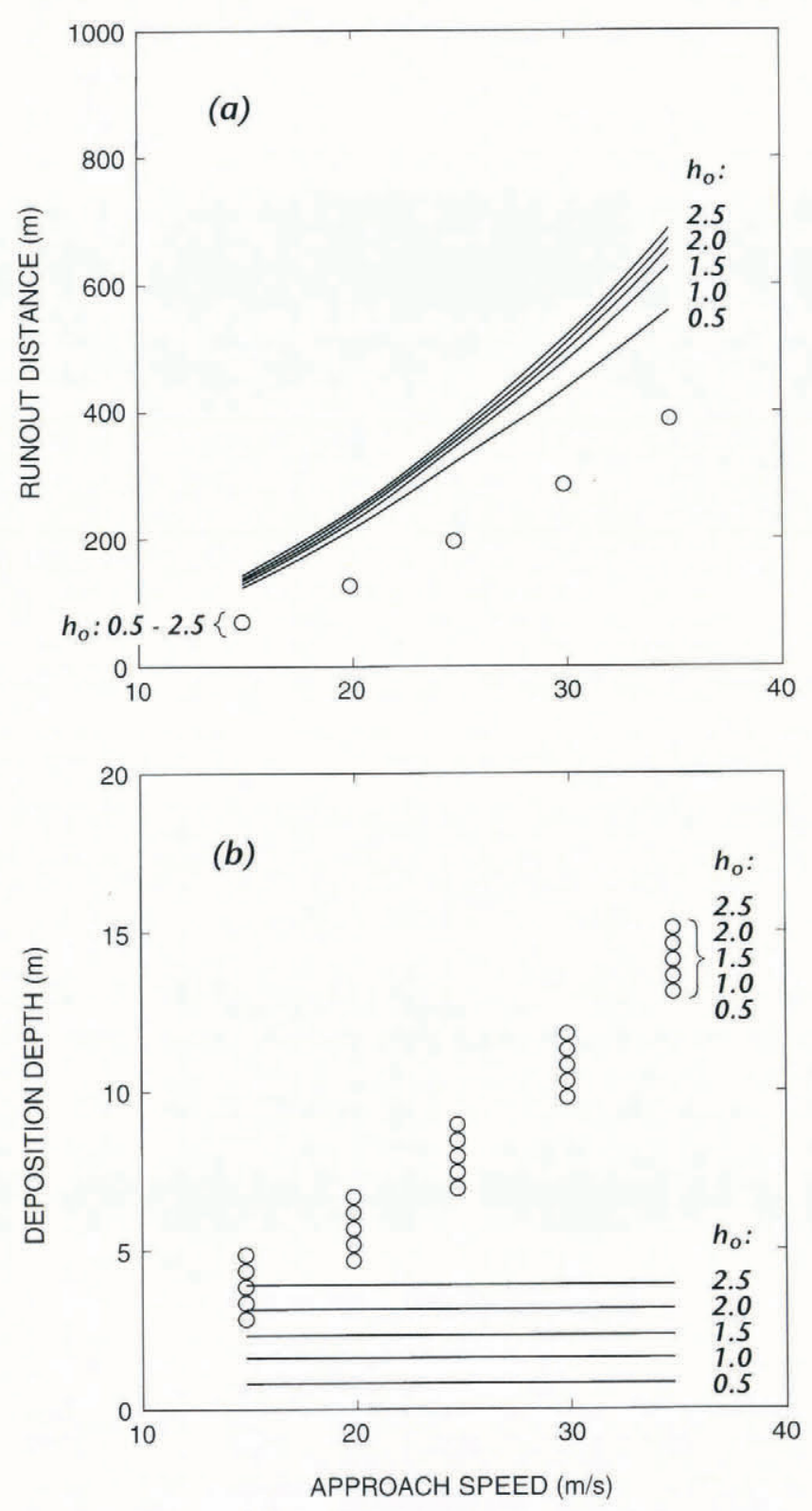

Fig. 4. (a) Run-out predictions for the leading-edge model (-) and the Swiss guidelines (centre-of-mass model) (O) as a function of approach-flow depth $\left(h_{0}\right)$ and approach speed $\left(v_{0}\right)$. Calculations are shown for $h_{0}=0.5$, 1.0, 1.5, 2.0 and $2.5 \mathrm{~m}$. Note that, for the friction parameters used, the Swiss guidelines run-out predictions are independent of initial flow depth if $v_{0}$ is specified. ( $b$ ) Deposition flow depths for the calculations in (a); $\psi_{0}=25^{\circ}, \quad \psi=8^{\circ}, \quad \xi=19620 \mathrm{~m} \mathrm{~s}^{-2}, \quad \mu=0.3$, $\phi=25^{\circ}$.

through the turbulent drag term (which is small in this example). For the results in Figure 4, the Swiss guidelines predict about half the run-out of the leading-edge model. For the leading-edge model, flow-depth dependence enters explicitly from the passive snow pressure.

Figure 5 shows a comparison of three models for runup calculations with $\mu=0.155, \xi=1000 \mathrm{~m} \mathrm{~s}^{-2}, \phi=25^{\circ}$, $\psi_{0}=10^{\circ}$ and $\psi=-30^{\circ}$. Included are: (1) the leadingedge model; (2) Equation (21) for Swiss guidelines runout adapted for an adverse slope ( $\psi$ negative), with $\cos \left(\psi_{0}-\psi\right) \rightarrow 1$ with $\bar{h}$ predicted by Equation (24); and
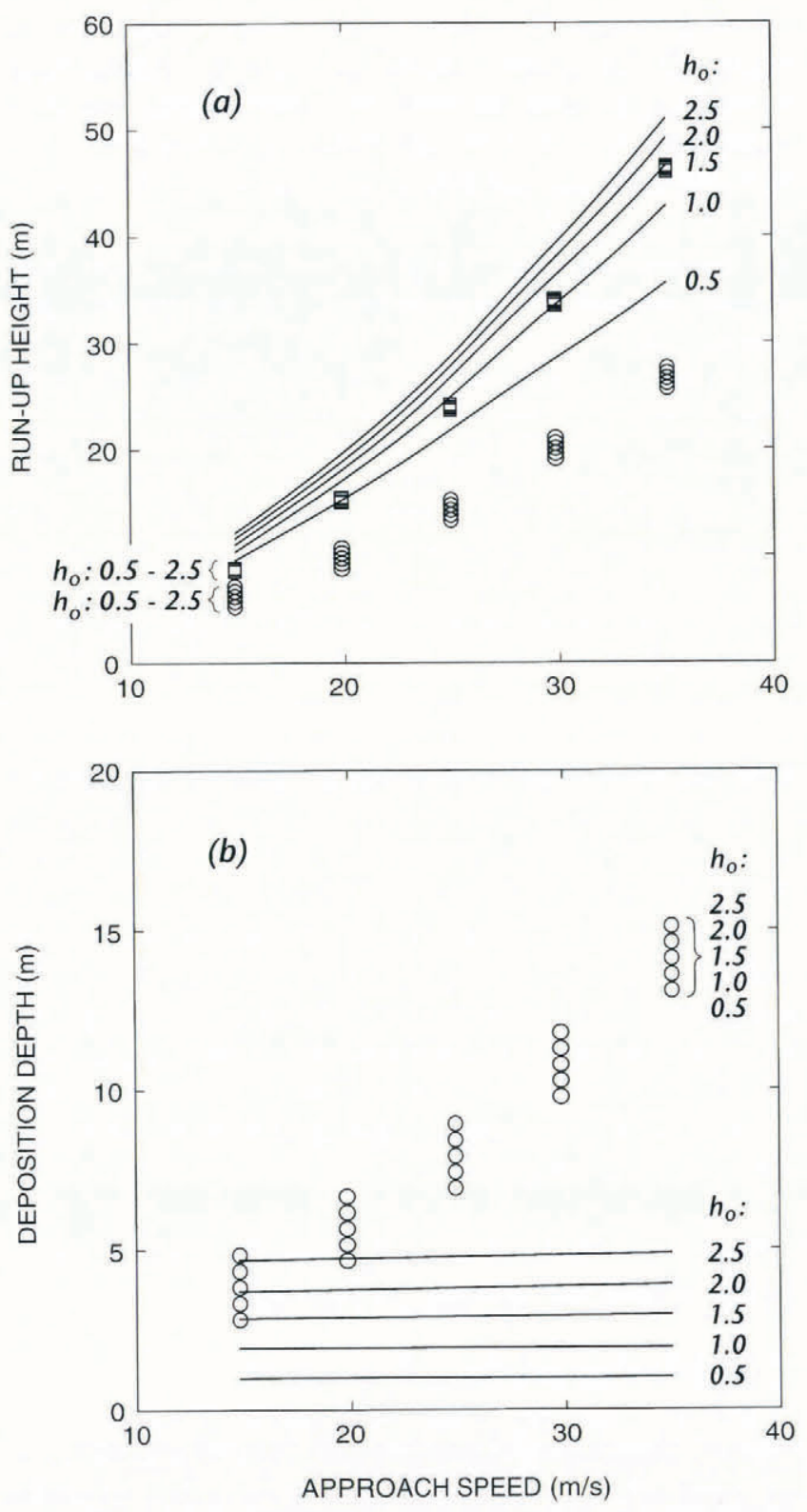

Fig. 5. (a) Run-up height as a function of approach speed and approach-flow depth. - leading-edge model; $\bigcirc$, Swiss guidelines (Equation (25)); and $\square$, Swiss guidelines run-out equations for an adverse slope (Equation (21) with $\cos \left(\psi_{0}-\psi\right) \rightarrow 1, D_{0}=g / \xi \bar{h}$, and Equation (24)). Initial flow depths used are $h_{0}=0.5,1.0,1.5,2.0$ and $2.5 \mathrm{~m}$. For all calculations: $\psi_{0}=10^{\circ}, \psi=-30^{\circ}, \mu=0.155, \xi=1000 \mathrm{~ms}^{-2}, \phi=$ $25^{\circ}$. (b) Deposition flow depths for the calculations in (a). - - leading-edge model; $\bigcirc$, Swiss guidelines (Equation (24)).

(3) Equation (25) as the recommendation for the Swiss guidelines. Since the guidelines contain assumptions of very high flow depths and there is no account of momentum loss at the slope angle transition, run-up is boosted to partially make up for higher energy loss in the centre-of-mass formulation contained in the guidelines. Figure 5 shows that the Swiss guidelines predict much lower run-up (Equation (25)). When run-out Equations (21) and (24) from the guidelines are used on the adverse slope, the predictions are comparable to the leading-edge model. This similarity results because $\cos \left(\psi_{0}-\psi\right)$ is 
assumed to be 1 and because very high flow depths are used in the guidelines. The final results from Equations (21) and (24) are essentially independent of initial flow depth for a given initial speed. Again, if the same friction coefficients and flow depths were used in the models (Equations (21) and (24) and Equations (7), (8) and (17)), the leading-edge model would predict about twice the run-up (Hungr and McClung, 1987).

Figure 6 gives calculations of $Q\left(\mathrm{~m}^{2} \mathrm{~s}^{-1}\right)$ : discharge per unit width as a function of incoming speed and mean deposition depth $(\mathrm{m})$ for three incoming speeds: 15, 25 and $35 \mathrm{~m} \mathrm{~s}^{-1}$. For the leading-edge model, Equation (17) is used, and for the Swiss guidelines Equation (24). Salm (1993) and H. Gubler (personal communication) have argued that the guidelines result in use of deposition depths (taken as a flow depth in dynamics calculations) which are too high; based on Figure 6, we agree. Again, when turbulent drag is important, run-out predicted by the guidelines is dependent on flow depth, and if very high flow depths are used run-out is increased in a manner that seems physically unrealistic by this mechanism.

\section{(ii) Field examples}

Field example 1: Battleship, Colorado, U.S.A. (February 1987) Figure 7 a gives the geometry of an example of avalanche run-up from the Battleship avalanche (February 1987) in Colorado, U.S.A. Speed estimates are available from timing the avalanche between known points on the path. In particular, it is estimated that the avalanche had a speed of about $45 \mathrm{~m} \mathrm{~s}^{-1}$ on entering the run-up segment. Total run-out along the slope was about $93 \mathrm{~m}$ with runup height being about $58 \mathrm{~m}$. The average slope angle along run-up was $-31^{\circ}$; average deposit depth was $1-5 \mathrm{~m}$. We estimated the basal friction coefficient, $\mu$, from the centre-of-mass model (McClung, 1990) by assuming an initial flow depth of $2-3 \mathrm{~m}$, with $\rho_{\mathrm{t}} / \bar{\rho}=0.1$, and $C_{\mathrm{D}}=0.01$ to give $D_{0} \bar{h}=0.0005$. With $D_{0} \bar{h}=0.0005$

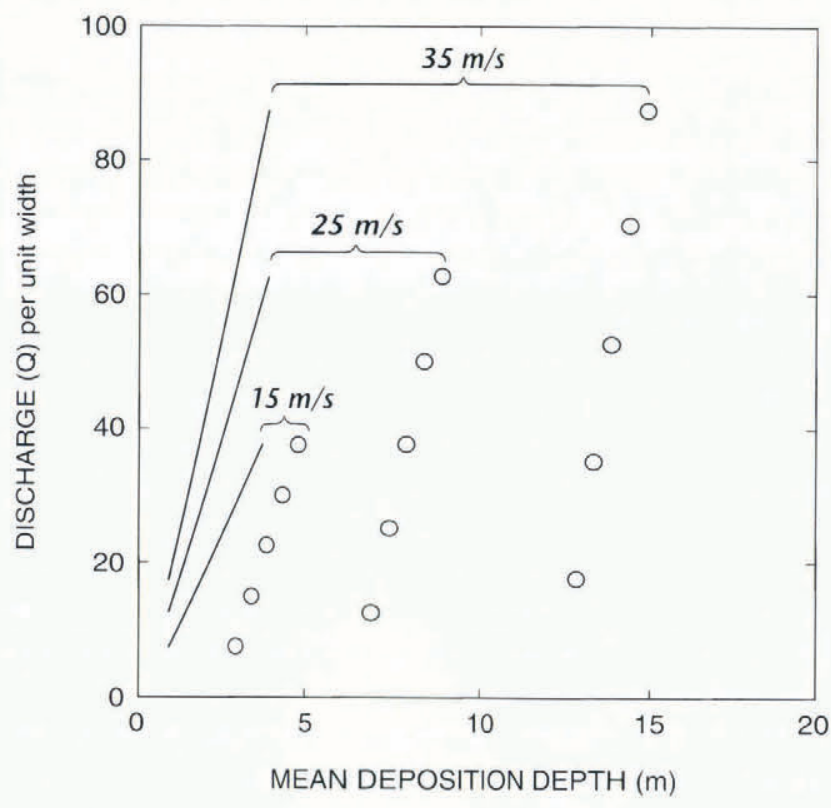

Fig. 6. Discharge per unil width ( $Q$ in $\mathrm{ms}^{-2}$ ) as a function of mean deposition depth for $v_{0}=15,25$ and $35 \mathrm{~m} \mathrm{~s}^{-1}$. - leading-edge model; $\bigcirc$, Swiss guidelines. $\psi_{0}=25^{\circ}, \psi=8^{\circ}, Q=v_{0} h_{0}, \phi=25^{\circ}$. Initial flow depths used are $h_{0}=0.5,1.0,1.5,2.0$ and $2.5 \mathrm{~m}$.

$\left(\mathrm{m}^{-1}\right)$ we found an approximate value for $\mu$ by selecting the value for which the two speed estimates $60 \mathrm{~ms}^{-1}$ reducing to $45 \mathrm{~m} \mathrm{~s}^{-1}$ ) are matched for the terrain in the track in between the two estimates. The initial flow depth was estimated by knowledge of the release volume $\left(2 \times 10^{5} \mathrm{~m}^{3}\right)$, the measured time for the volume to flow through the lower track and the confined path geometry. The fracture depth averaged about $1 \mathrm{~m}$, but we estimated the flow depth to be $2-3 \mathrm{~m}$ on entering the run-up slope. This gave the estimated friction coefficients of $\mu=0.32$; $D_{0} \bar{h}=0.0005\left(\mathrm{~m}^{-1}\right)$ or $\xi=19620 \mathrm{~m} \mathrm{~s}^{-2}$ for use in the
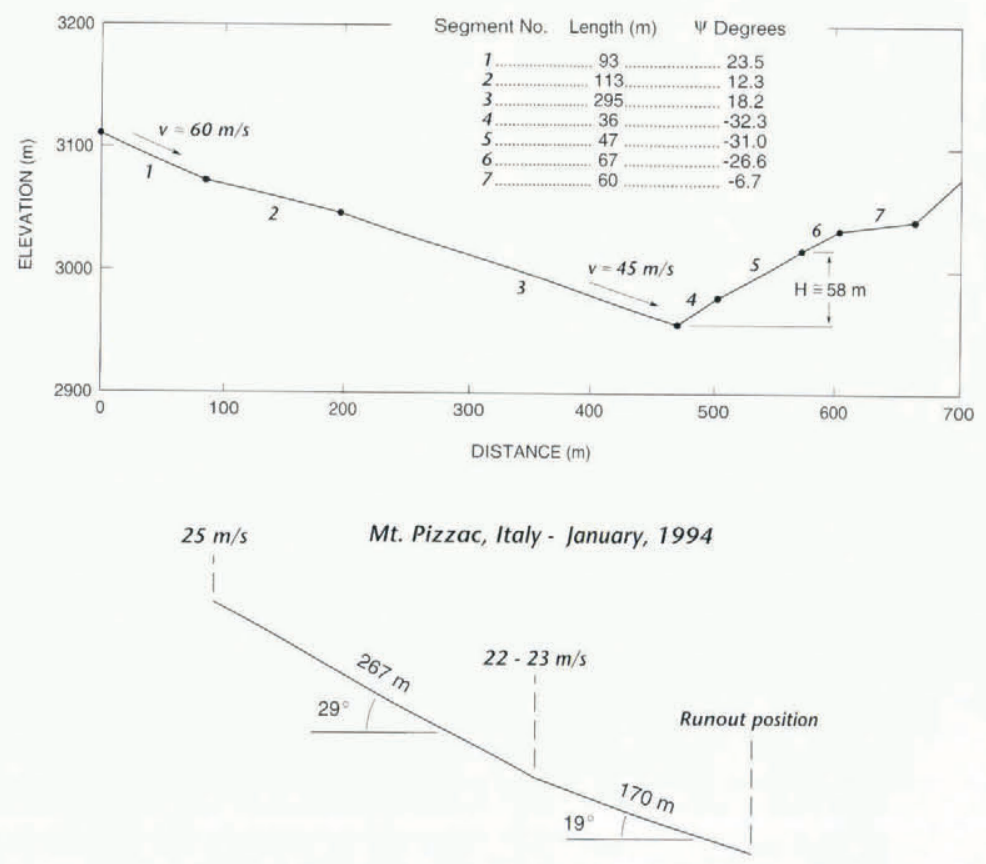

Fig. 7. (a) Slope profile, speed estimates and run-up for the Batlleship avalanche, February 1987. (b) Slope profile, speed estimates and run-out for Mount Pizzac avalanche, January 1994. 
run-up calculations. We assume $\phi=25^{\circ}$ to give $k_{\mathrm{p}}=1.87$. Model calculations gave: $\mu=0.32 ; D_{0}=0.0005 / 2.28=$ $0.0002\left(\mathrm{~m}^{-1}\right) ; \bar{h}=4.5 \mathrm{~m} \quad\left(h_{0}=2 \mathrm{~m}\right)$; run-up $=57 \mathrm{~m}$. For the same parameters, except $h_{0}=3 \mathrm{~m}$, we get $\bar{h}=6.8 \mathrm{~m}$, run-up $=58 \mathrm{~m}$. In this example, the agreement is very close to the observed run-up, and we believe it is fortuitous because of all the uncertainties in parameter estimates and incoming speeds.

If we assume Equation (25) to represent run-up for the Swiss guidelines, we estimate $\left(v_{0}=45 \mathrm{~m} \mathrm{~s}^{-1} ; \phi=25\right.$ 잉 $\left.(\lambda=2.5), h_{0}=2 \mathrm{~m}\right)$ run-up $=43 \mathrm{~m}$. For the same parameters, except $h_{0}=3 \mathrm{~m}$, we get run-up $=44 \mathrm{~m}$.

From the run-out, equations for the Swiss guidelines (Equations (21) and (24)) are applied, with $\psi_{0}=\psi$, $\mu=0.32, \xi=19620 \mathrm{~ms}^{-2}, h_{0}=2$ or $3 \mathrm{~m}$ and $\lambda=2.5$; we get run-up $=67 \mathrm{~m}$ for both $\bar{h}=22.6 \mathrm{~m}\left(h_{0}=2 \mathrm{~m}\right)$ and $\bar{h}=23.6 \mathrm{~m}\left(h_{0}=3 \mathrm{~m}\right)$.

If we use friction coefficients recommended in the guidelines and Salm (1993) in Equations (21) and (24), $\mu=0.155, \xi=1000 \mathrm{~ms}^{2}, \lambda=2.5\left(\phi=25^{\circ}\right)$ and $h_{0}=$ $2 \mathrm{~m}$, we get run-up $=77 \mathrm{~m}, \bar{h}=22.6 \mathrm{~m}$. For both sets of friction coefficients, Equations (21) and (24) overestimate run-up because very high flow (mean-deposition) depths are used in the calculations (much higher than observed) and because all the momentum is taken to be conserved on the run-up slope, instead of just the slope-parallel component. Granular-flow experiments by Chu and others (1995) show the importance of taking only the slope-parallel component in run-up problems.

\section{Field example 2: Mount Pizzac, Italy (Jamuary 1994)}

Figure $7 \mathrm{~b}$ shows geometry for the slope profile above and in the run-out zone for Mount Pizzac. The avalanche was small with a volume of $2000 \mathrm{~m}^{3}$ and was triggered by explosives (Natale and others, 1994). Average slope angle for $267 \mathrm{~m}$ above the last measurement point was $29^{\circ}$. The estimated speed at the final measurement point was 22 $23 \mathrm{~m} \mathrm{~s}^{-1}$, and the speed approaching the calibration zone $267 \mathrm{~m}$ above the last measurement point was $25 \mathrm{~m} \mathrm{~s}^{-1}$. We assume $C_{\mathrm{D}}=0.01$, and $\rho_{\mathrm{t}} / \rho=0.1$, to give $\xi=19620 \mathrm{~m} \mathrm{~s}^{-2}, \quad D_{0} \bar{h}=0.0005 \mathrm{~m}^{-1}$, as in previous examples. With this assumption about turbulent drag, if the speed drops from 25 to $22 \mathrm{~m} \mathrm{~s}^{-1}$ over the $267 \mathrm{~m}$ interval upslope of the run-out calculation point, we estimate from our model that $\mu=0.6$, and this estimate along with $\xi=19620 \mathrm{~m} \mathrm{~s}^{-2}$ is used in the run-out calculations. To estimate passive pressure, we assume $\phi=25^{\circ}$, and since $\psi_{0}=29^{\circ}$, i.e. greater than $25^{\circ}$, we assume $k_{\mathrm{p}}=1$ (from Equation (6)). Measured flow depth approaching the run-out zone was $1 \mathrm{~m}$, and we used this value for $h_{0}$ in our calculations.

With the above inputs, the calculations from our model yield: $\bar{h}=1.5 \mathrm{~m}$ (maximum flow depth measured was $2.5 \mathrm{~m}$ ), run-out $190 \mathrm{~m}$ (if $v_{0}=22 \mathrm{~m} \mathrm{~s}^{-1}$ ) or $207 \mathrm{~m}$ (if $v_{0}=23 \mathrm{~m} \mathrm{~s}^{-1}$ ) beyond the last measurement point. Measured run-out distance was $170 \mathrm{~m}$. For this example, the calculated mean (or deposition) flow depth is less than the measured maximum depth. The run-out distance is overestimated but the differences are well within the range of uncertainty of the model parameter inputs. In Appendix B, we offer a partial explanation for the overestimate: for such a small avalanche the supply (or discharge) may decrease with time, resulting in shorter run-out. This example is the only one we have found for which there are reasonably accurate measurements of speeds, flow depths and geometry to enable all model parameter inputs to be measured.

This avalanche is very small and does not fit the Swiss guidelines for extreme avalanches. According to the guidelines, an extreme avalanche would not stop on a slope of $19^{\circ}$. Our model is more general; it can be used to predict run-out or run-up for even small dry-flowing avalanches, provided input parameters can be estimated and the basic assumptions are satisfied as well.

\section{Field examples 3 and 4: Aulla, Swilzerland (8 and 10 February} 1984)

Salm and Gubler (1985) and Gubler and others (1986) documented speeds, initial fracture depths, run-out and path geometry for two avalanches on the Aulta avalanche path. We have used our model to predict the run-out. For both avalanches we assume $\phi=25^{\circ}$, and $h_{0}=1 \mathrm{~m}$ (close to estimated fracture depths). For both avalanches, we assume $\xi=19620 \mathrm{~ms}^{2}$, as in previous comparisons, and have estimated the friction coefficient $\mu$ by using speeddeceleration information and path geometry in our model prior to the point at which we begin our run-out calculations. Both examples from Aulta have high uncertainty because neither run-out is well documented. In addition, the avalanche path has a gully in the final stages which opens up in the run-out area. Caution should therefore be used when taking these examples to support our model.

Figure 8 a shows path geometry, speed estimates and run-out position for the 8 February avalanche Gubler and others, 1994). The speed drops from about 55 to $45 \mathrm{~m} \mathrm{~s}^{-1}$ over a horizontal reach distance of about $480 \mathrm{~m}$. From these data and the assumptions above, we estimate $\mu=0.4$. For the run-out (run-up) calculations, we take $\psi_{0}=0^{\circ} ; \psi=-12^{\circ}, v_{0}=26 \mathrm{~ms}^{-1}$. When input in our model, these estimates gave a run-out distance of $110 \mathrm{~m}$
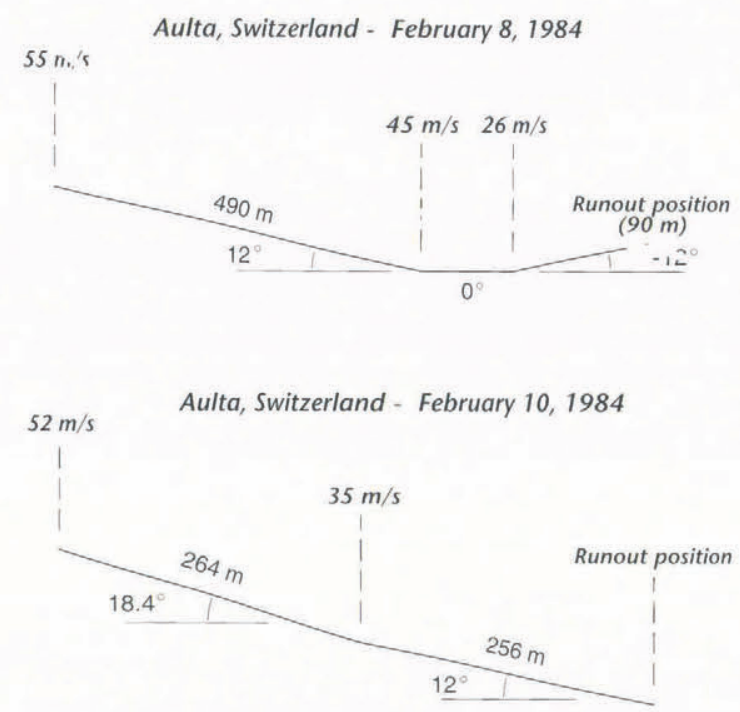

Fig. 8. (a) Slope profile, speed estimates and run-out for the Aulta avalanche, 8 February 1984. (b) Slope profile, speed estimates and run-out for the Aulta avalanche, 10 February 1984. 
which compares favourably with the measured estimate of about $90 \mathrm{~m}$.

Figure $8 \mathrm{~b}$ shows path geometry, speed estimates and run-out position for the 10 February avalanche. The speed drops from about 52 to $35 \mathrm{~m} \mathrm{~s}^{-1}$ over a horizontal distance of $250 \mathrm{~m}$ on a slope with mean angle of $18.4^{\circ}$. With the assumption $\xi=19620 \mathrm{~ms}^{2}$, from our model, we estimate $\mu=0.7$, using $\phi=25^{\circ}$, and $h_{0}=1 \mathrm{~m}$. For the run-out calculations, we take $\psi_{0}=18.4^{\circ}, \psi=12^{\circ}$. These assumptions give: $\bar{h}=1.5 \mathrm{~m}$, run-out $=244 \mathrm{~m}$. The measured run-out distance is about $260 \mathrm{~m}$ (Salm and Gubler, 1985; Gubler and others, 1986).

\section{SUMMARY}

We have presented a method for calculating run-up and run-out in the deceleration phase of avalanche motion. Our method applies only to the important but restricted case in which initial conditions can be estimated: incoming speed, incoming flow depth, friction coefficients and internal friction. Our method is similar in spirit to that proposed in the Swiss guidelines Salm and others, 1990), but the modelling details differ. Some differences include:

(1) Instead of a centre-of-mass model, as in the Swiss guidelines, we calculate the stopping position of the tip of the avalanche by simultaneous solution of the momentum and continuity equations. The implication is that, given the same friction conditions and flow depth, our model gives longer and more conservative) run-out. Similar findings are reported by Salm (1993) for another model which takes into account momentum and continuity: longer run-out is predicted.

(2) We estimate mean deposition depth or mean run-out zone flow depth) from supply as proposed by Salm (1993). This (approximate) estimate gives reasonable flow depths which are used in the calculations. According to Salm (1993) and H. Gubler (personal communication), the deposition depths (Equation (24)) used in the calculations for the Swiss guidelines from engineering-hydraulics analogy are unrealistically high. The application of these high flow depths in the guidelines causes increases in run-out to partially make up for difference (1).

(3) In our model, we are able to input passive snow pressure directly, and in doing so we have also accounted for slope-angle dependence. The Swiss guidelines is a center-of-mass (or lumped-mass) model, into which only external forces may be input: there is no way of accounting for passive snow pressure explicitly. Instead, the Swiss guidelines input passive snow pressure implicitly through flow-depth dependence using an engineering-hydraulics argument. Salm (1993) constructed a model as an alternative to the Swiss guidelines which did include passive snow pressure explicitly.

(4) We have introduced slope-angle corrections into our model to account for momentum losses due to slopeangle decreases in run-out or run-up (adverse-slope) problems. This effect will be most important in run-up at sharply increasing slope-angle changes. Granularflow experiments (Chu and others, 1995) in a flume show that this effect is important at sharp slope-angle transitions. For the run-up example from Battleship, Colorado, the equations adapted from the Swiss guidelines (Equations (21) and (24)) produce reasonable results for two reasons:

(a) momentum loss at the slope-angle transition was not accounted for;

(b) unrealistically high deposition depths are predicted.

These two effects increase the run-up to compensate for the fact that the centre-of-mass model will normally produce lower run-up.

Our limited experience with the run-up Equation (25) proposed in the Swiss guidelines suggests that it may underestimate run-up. This belief is based on model comparison as well as the example from the Battleship avalanche, Colorado. In a previous study Chu and others, 1995) for granular flows in a flume, it was shown that during run-up there is a tendency for material to be deposited at a sharp slope-angle transition, with maximum run-up occurring by material overriding that trapped at the corner. The implication is that run-up in very sharp slope-angle transitions may exceed even that for the leading-edge run-up equations we have proposed Chu and others, 1995). Therefore, it is possible that in some field examples Equation (25) may underestimate run-up even more than in the Battleship example. Our model does not contain a mechanics formulation sophisticated enough to be applied when the slope-angle transition approaches $90^{\circ}$. Equation 25 from the Swiss guidelines contains no explicit slope-angle dependence. It must be kept in mind that the formulation we have proposed here is one-dimensional. Neither it nor that for the Swiss guidelines is designed to handle the twodimensional and three-dimensional features which can be important in run-out and run-up for real avalanches. A disadvantage of our formulation compared to the Swiss guidelines is that, in general, no analytic solutions are available when turbulent drag is important. Numerical solutions are easy to obtain, however, and it is likely that in the future numerical solutions will be required when two- or three-dimensional aspects of the problem are incorporated.

We believe that our formulation as applied in this paper is more suitable for run-up than run-out. Surely, the basal friction conditions will change as the avalanche mass decelerates and stops, which implies that the friction coefficient $\mu$ may need to be varied along the run-out zone (McClung, 1990). Since run-up slope distances are shorter than run-out distances, basal friction variations during deposition may not be as serious in run-up. If theoretical estimates of friction-parameter variations along the run-out zone were known, it would be easy to incorporate them in our numerical solution scheme.

Another reason our formulation is more suitable for run-up than run-out is our assumption of constant discharge (or supply) in the derivation of the momentum Equation (7). This assumption is closer to being satisfied for run-up or for large avalanches. If the discharge 
decreases with time, the momentum flux (term $T_{2}$ ) would have to be reduced with time in Equation (7). Such modification would, however, result in prediction of shorter run-out distances. Therefore, our assumption of constant supply (or discharge) instead of decreasing discharge with time is likely to produce conservative estimates of run-out, which is usually an advantage in engineering calculations. See Appendix B for details.

Aside from the modelling differences described above, our view about the values of the friction coefficients $\mu$ and $\xi$ (or $D_{0} \bar{h}$ ) is different from that of Salm and others (1990) and Salm (1993). We believe that basal friction in runout and run-up can be accounted for almost entirely by the dynamic Coulomb friction coefficient $\mu$, with $\xi$ (or $D_{0} \bar{h}$ ) playing only a role as turbulent friction at the upper surface of the flowing mass. Our view is conditioned by the results of Dent $(1986,1993)$ showing how basal shear and normal forces can be coupled in a dense, rapidly deforming granular material such as we envision for avalanching material in run-out and run-up problems. The model of McClung (1990) for estimating speeds all along the incline is also based on the concept that shear and normal forces are entirely coupled at the lower basal boundary. Since the basal friction conditions in dryflowing avalanches have never been measured, we must rely at this point on physical principles and models for information about basal friction mechanisms. This uncertainty should not detract from the model we have presented. If turbulent drag does play a significant role in basal friction (e.g. Salm, 1993), our model can still be applied, and indeed we have presented example calculations in our paper to represent this alternative view. Regardless of which of these two pictures is most nearly correct, large-scale roughness features will also play a role in basal friction (Salm, 1993), and no theoretical model exists for proper inclusion of this effect.

Salm (1993) showed that the run-out estimates of the Swiss guidelines are very sensitive to initial flow depth. His calculations for the Ariefa avalanche in Switzerland, for example, showed an increase of $200 \mathrm{~m}$ run-out with an initial flow-depth increase from 0.8 to $1.0 \mathrm{~m}$. This effect is found to some degree in our model as well, but it is highly dependent on the choice of friction coefficients: $\mu$ and $D_{0} \bar{h}$ (or $\xi$ ) taken for model comparisons. From Figures 3 and 4, we show that given an initial approach speed the equations of the Swiss guidelines are essentially independent of initial flow depth when turbulent drag is small (Fig. 4) (we believe that turbulent drag should be small in run-up and run-out). When turbulent drag is small, our model shows increasing run-out distance with increasing flow depth (Fig. 4), but the sensitivity is not large. This flow-depth dependence results because we are able to input passive snow pressure explicitly. Our analysis, together with Salm's example, field observations and examples such as Battleship, Colorado, reinforces our belief that turbulent drag is small in run-out and run-up. Run-out and run-up should depend on initial flow depth, but the sensitivity implied in the models with respect to flow-depth dependence, when turbulent drag is taken to be significant, seems too great in our experience.

\section{ACKNOWLEDGEMENTS}

We are grateful for the ideas of Dr B. Salm, Swiss Federal Institute for Snow and Avalanche Research. This research was sponsored by the Natural Sciences and Engineering Research Council of Canada (NSERC). We thank NSERC for support of this and other avalanche research in western Canada. Special thanks are owed to L. Nettuno, University of Pavia, Italy, and Dr H. Gubler, Davos, Switzerland, for supplying field examples.

\section{REFERENCES}

Chu, T., G. Hill, D. M. McClung, R. Ngun and R. Sherkat. In press. Granular flow measurements for avalanche run-up. Can. Geotech. J.

Craig, R. F. 1988. Soil mechanics. London, Van Nostrand Reinhold (International).

Daugherty, R. L., J.B. Franzini and E.J. Finnemore. 1985. Fluid mechanics with engineering applications. Eighth edition. New York, McGraw-Hill.

Dent, J.D. 1986. Flow properties of granular materials with large overburden loads. Acta Mech., 64, 111-122.

Dent, J.D. 1993. The dynamic friction characteristics of a rapidly sheared granular material applied to the motion of snow avalanches. Ann. Glaciol., 18, 215-220.

Gubler, H., M. Hiller, G. Klausegger and U. Suter. 1986. Messungen an Fliesslawinen. Mitteilungen des Eidgenössischen Institutes für Schnee- und Lawinenforschung 41.

Hungr, O. and D. M. McClung. 1987. An equation for calculating snow avalanche run-up against barriers. International Association of Hydrological Sciences Publication 162 (Symposium at Davos 1986-Avalanche Formation, Movement and Effects), 605612.

McClung, D. M. 1987. Mechanics of snow slab failure from a geotechnical perspective. International Associalion of Hydrological Sciences Publication 162 Symposium at Davos 1986-Avalanche Formation, Movement and Effects), 475-508.

McClung, D. M. 1990. A model for scaling avalanche speeds. J. Glaciol., 36(123), 188-198.

McClung, D. M. and P.A. Schaerer. 1985. Characteristics of flowing snow and avalanche impact pressures. Ann. Glaciol., 6, 9-14.

McClung, D. and P. Schaerer. 1993. The avalanche handbook. Seattle, WA, The Mountaineers.

Natale, L., L. Nettuno and F. Savi. 1994. Numerical simulation of dense snow avalanches: an hydraulic approach. International Association of Science and Technology Development - International Conference on Modelling and Simulation - MS'94, Pittsburgh, PA, May 2 4, 1994, $233-236$.

Perla, R., T. T. Cheng and D. M. McClung. 1980. A two-parameter model of snow avalanche motion. J. Glaciol., 26 94), 197-207.

Salm, B. 1966. Contribution to avalanche dynamics. International Association of Scientific Hydrology Publication 69 (Symposium at Davos 1965 - Scientific Aspects of Snow and Ice Avalanches), 199-214.

Salm, B. 1993. Flow, flow transition and runout distances of flowing avalanches. Ann. Glaciol., 18, 221-226.

Salm, B. Unpublished. Fliessübergänge und Auslaufstrecken von Lawinen. Eidgenössisches Institut für Schnee- und Lawinenforschung. Interner Bericht 566, 1979.

Salm, B., A. Burkard and H. Gubler. 1990. Berechnung von Fliesslawinen; eine Anleitung für Praktiker mit Beispielen. Mitteilungen des Eidgenössischen Institutes für Schnee- und Lawinenforschung 47.

Schlicting, H. 1972. Boundary layer theory. New York, McGraw-Hill.

Takahashi, T. 1991. Debris flow. Rotterdam, A.A. Balkema. (IAHR Monograph.)

Takahashi, T. and H. Yoshida. 1979. Study on the deposition of debris flows. Part 1. Deposition due to abrupt change of bed slope. Disaster Prevention Research Institute. Annals (Kyoto) 22B-2. [In Japanese with English summary.]

Voellmy, A. 1955. Uber die Zerstörungskraft von Lawinen. Schweiz. Bauzlg., 73, 159-165, 212-217, 246-249, 280-285. 


\section{APPENDIX A}

\section{ESTIMATE OF TURBULENT DRAG COEFFICIENT}

In our formulation, the quantity $D_{0} \bar{h}$ is represented by:

$$
D_{0} \bar{h}=\frac{1}{2}\left(\frac{\rho_{\mathrm{t}}}{\bar{\rho}}\right) C_{\mathrm{D}}=\frac{g}{\xi} .
$$

Solving for $\xi$ gives:

$$
\xi=2\left(\frac{\bar{\rho}}{\rho_{\mathrm{t}}}\right) \frac{g}{C_{\mathrm{D}}} .
$$

If $\bar{\rho} / \rho_{\mathrm{t}} \simeq 0.1$ and if $C_{\mathrm{D}} \simeq 0.01$, calculation gives: $\xi=19620 \mathrm{~ms}^{2}$. This result contains the assumption that turbulent drag acts at the top (upper surface) of the flow. If $\bar{\rho} / \rho_{\mathrm{t}}=1$ (turbulent drag is assumed to act at the base of the flow only), then $\xi=1962 \mathrm{~m} \mathrm{~s}^{-2}$ (or $982 \mathrm{~ms}^{-2}$ if $C_{\mathrm{D}}=0.02$, nearly equivalent to Salm's estimate of $\left.1000 \mathrm{~ms}^{2}\right)$. Both our model and the prescription given by Salm (1993) contain the assumption that $C_{\mathrm{D}} \approx 0.01$ to 0.02 , which is equivalent to a coefficient (Schlicting, 1972) for turbulent flow over a rough boundary. The important difference between these results stems from our belief that for flowing avalanches, particularly in run-out and run-up problems, turbulent drag is negligible at the base of the flow. We believe that the high volume fraction filled by solid materials (up to $50 \%$ ) will prevent turbulence from forming in the interstitial air between the particles and that momentum will be transferred by particle collisions and rubbing friction. Due to the large difference in density between the particles and the air (ratio 100 to 1000 ), we believe that the presence of the air at the base of the flow will play a negligible role in the mechanics of run-up and run-out problems.

\section{APPENDIX B}

\section{MOMENTUM PRINCIPLE APPLIED TO AVALANGHE DYNAMICS}

Following Daugherty and others (1985), we consider an avalanche mass contained at time $t$ in a control volume which is fixed in position. At time $t+\Delta t$, the avalanche mass has moved to a new position along the run-out or run-up slope. At time $t=0$, the tip of the avalanche mass is just coincident with the start of the run-out or run-up slope (see Fig. 9).

Definitions of important quantities are:
$(m \mathbf{V})_{t}$
$=$ momentum of entire avalanche mass at time $t$
$(m \mathbf{V})_{t+\Delta t}=$ momentum of entire avalanche mass at time $t+\Delta t$
$\left(m^{\prime} \mathbf{V}^{\prime}\right)_{t}$
$=$ momentum of avalanche mass within the
$\left(m^{\prime} \mathbf{V}^{\prime}\right)_{t+\Delta t}$ control volume at time $t$
$\Delta(m \mathbf{V})_{\text {out }} \quad=$ momentum of avalanche mass that leaves the control volume during $\Delta t$
$\Delta(m \mathbf{V})_{\text {in }} \quad=$ momentum of avalanche mass that enters the control during $\Delta t$.

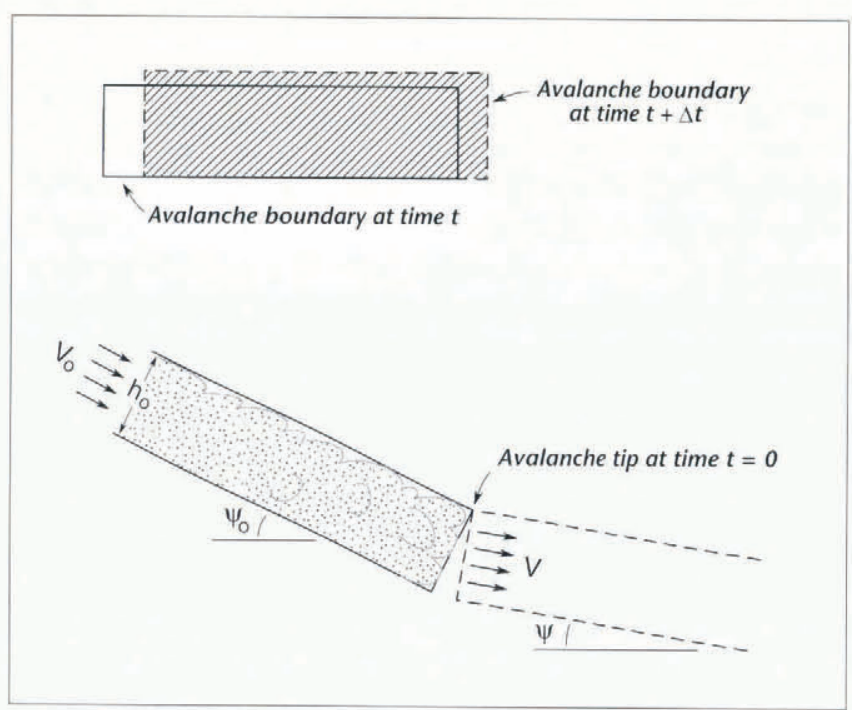

Fig. 9. Schematic of fixed control volume for momentum principle at run-out (or run-up) slope.

At time $t$, by definition, $(m \mathbf{V})_{\mathrm{t}}=\left(m^{\prime} \mathbf{V}^{\prime}\right)_{\mathrm{t}}$. At time $t+\Delta t$ (shaded portion of Figure 9), the momentum of the entire avalanche mass is the sum of the momentum within the control volume at $t+\Delta t$, plus the momentum that has flowed out of the control volume during $\Delta t$, minus the momentum that has flowed into the control volume (unshaded area of Figure 9) during $\Delta t$. This balance may be written:

$$
(m \mathbf{V})_{t+\Delta t}=\left(m^{\prime} \mathbf{V}^{\prime}\right)_{t+\Delta t}+\Delta(m \mathbf{V})_{\text {out }}-\Delta(m \mathbf{V})_{\text {in }} .
$$

Therefore, the change of momentum of the avalanche mass is:

$$
\Delta(m \mathbf{V})=(m \mathbf{V})_{t+\Delta t}-(m \mathbf{V})_{\mathrm{t}} .
$$

Combining these expressions and substituting into Newton's second law, we get:

$$
\begin{aligned}
\Sigma \mathbf{F} & =\lim _{\Delta t \rightarrow 0} \frac{\Delta(m \mathbf{V})}{\Delta t}=\frac{\mathrm{d}(m \mathbf{V})}{\mathrm{d} t} \\
& =\frac{\mathrm{d}(m \mathbf{V})_{\text {out }}-\mathrm{d}(m \mathbf{V})_{\text {in }}}{\mathrm{d} t}+\frac{\left(m^{\prime} \mathbf{V}^{\prime}\right)_{t+\Delta t}-\left(m^{\prime} \mathbf{V}^{\prime}\right)_{t}}{\mathrm{~d} t}
\end{aligned}
$$

where $\Sigma \mathbf{F}$ is the vector sum of all forces acting on the avalanche mass including gravity, drag at the top and bottom and passive snow pressure.

Equation (B3) is a perfectly general momentum principle (Daugherty and others, 1985). It applies for compressible or incompressible flow, and steady or unsteady flow. For steady flow, which we assume in this paper, the momentum balance becomes:

$$
\Sigma \mathbf{F}=\frac{\mathrm{d}(m \mathbf{V})_{\text {out }}}{\mathrm{d} t}-\frac{\mathrm{d}(m \mathbf{V})_{\text {int }}}{\mathrm{d} t}
$$

because the last term of Equation (B3) is zero. Equation (B4) states that, for steady flow, the sum of the forces on the avalanche mass is equal to the net rate of outflow of momentum across the original (fixed) control surface. The second term in Equation (B4) represents the 
momentum rate or momentum flux into the control volume from oncoming avalanche material reaching the beginning of the run-out slope (control volume): it is a physically necessary force which cannot be neglected.

For our model, we have assumed an incompressible flow in one dimension and we have implicitly taken the velocity as the mean value over the face of the control volume. The rate of momentum transfer into the control volume (momentum flux) is given by $\left(\bar{\rho} v_{0} \mathrm{~d} A\right) v_{0}$ where $\mathrm{d} A$ is the element of area on the face of the control volume. The rate of momentum transfer across the entire area (per unit width) is then $\bar{\rho} v_{0}{ }^{2} h_{0}$ : the second term in Equation (B4) (see Fig. 2). For a run-up (or adverse) slope, however, we assume that only the component of momentum parallel to the slope is effective in pushing the avalanche mass forward (the force component perpend- icular to the control-volume face). With respect to Figure 2 , this gives $\bar{\rho} v_{0}{ }^{2} h_{0} \cos \left(\psi_{0}-\psi\right)$ : term $T_{2}$ in Equation (7). All the other terms in Equation (7) came from the lefthand side of Equation (B4): gravity, forces at the top and bottom and passive snow pressure.

From Equation (B4), if the momentum flux into the control volume (discharge or supply) decreases with time, as might happen some time after the passage of the avalanche front, the momentum rate out of the control volume also reduces with time. For our model, such a situation would imply reduced run-out distance. Therefore, our assumption of constant discharge is a conservative one from the perspective of run-out: our calculated run-out distances may exceed the real ones. It is important to remember that other uncertain features of the avalanche-dynamics problem may mask this effect.

MS received 4 July 1994 and accepted in revised form 21 September 1994 